\title{
Political Violence and Religion in Europe
}

\author{
Juan S. Fernández-Prados ${ }^{1}$, Antonia Lozano-Díaz ${ }^{2}$, Alexandra Ainz-Galende ${ }^{3}$ \\ University of Almeria (Spain)
}

\begin{abstract}
The fifth wave and latest European Values Study (2017-18) offers once again the opportunity to analyze the values, beliefs, opinions, attitudes and behaviors of European societies. One of the challenges facing the European Union is the political violence manifested in the emergence of the extreme right (Rydgren, 2018), radical protests (Rak, 2018) or fundamentalist terrorisms (Sageman, 2017). Although violence is increasingly studied, it is very difficult to define especially when it responds to collective actors or social groups, however, we can agree that political violence is the violent action of organized groups to modify power structures (Moreno, 2009). In this communication we intend to carry out a descriptive and explanatory approach to the justification of political violence (within question 44 of the European Values Study). Within the set of explanatory variables, we will dwell on the role played by religion in its different aspects (importance of religion and god, belonging to religious organizations, religious practice, religious confession, trust in other religions, etc.) (Aslan \& Hermansen, 2017; Dingley \& Mollica, 2018).
\end{abstract}

Keywords: religious violence; radical religion; European Values Study; Muslim; Christian. 